\title{
Population Pharmacokinetic Modeling of Benralizumab in Adult and Adolescent Patients with Asthma
}

\author{
Li Yan $^{1} \cdot$ Bing Wang ${ }^{1} \cdot$ Yen Lin Chia ${ }^{1} \cdot$ Lorin K. Roskos $^{2}$
}

Published online: 11 March 2019

(c) The Author(s) 2019

\begin{abstract}
Introduction Benralizumab, an interleukin-5 receptor alpha-directed cytolytic anti-eosinophil monoclonal antibody, was recently approved as add-on maintenance treatment for patients aged 12 years and older with uncontrolled asthma with eosinophilic inflammation.

Methods Pharmacokinetic (PK) data from nine clinical trials for patients with asthma were pooled and analyzed to further characterize the PK of benralizumab and evaluate demographic covariate effects.

Results Population modeling results demonstrated that the PK of benralizumab were dose-proportional across a wide dosage range and were adequately described by a two-compartment model with first-order absorption from the subcutaneous dosing site and a first-order elimination pathway from the central compartment. Following subcutaneous administration, the absorption half-life of benralizumab was 3.54 days, and the absolute bioavailability was $58.9 \%$. Estimated clearance (CL; $0.291 \mathrm{~L} /$ day $)$, central volume of distribution $\left(\mathrm{V}_{\mathrm{c}} ; 3.13 \mathrm{~L}\right)$, and peripheral volume of distribution $\left(\mathrm{V}_{\mathrm{p}} ; 2.52 \mathrm{~L}\right)$ were typical for therapeutic immunoglobulins. Elimination half-life was approximately 15.5 days for patients with asthma. Age, sex, race, liver function, renal function, baseline blood eosinophil count, anatomic injection site, and commonly used small-molecule drugs had no clinically relevant impact on benralizumab CL. Only body weight and antidrug antibodies (ADAs) were identified as relevant PK covariates. Power parameters (exponent) of body weight on $\mathrm{CL}, \mathrm{V}_{\mathrm{c}}$, and $\mathrm{V}_{\mathrm{p}}$ were $0.807,0.803$, and 0.528 , respectively, and the presence of ADAs increased benralizumab CL by $124 \%$.

Conclusions Over 5-20 weeks, the PK of benralizumab were dose-proportional across a dosage range of $0.03-3 \mathrm{mg} / \mathrm{kg}$ intravenously and 2-200 mg subcutaneously administered every 4 weeks or every 8 weeks (first three doses every 4 weeks). Body weight and ADA status were identified as relevant PK covariates. Baseline eosinophil count, hepatic and renal functions, anatomical subcutaneous injection site, and commonly used small-molecule drugs had no impact on the PK of benralizumab.
\end{abstract}

\footnotetext{
In memoriam: The authors pay tribute to Matt Hutmacher, who passed away before the development of this publication. Dr. Hutmacher was an expert in the field of pharmacometrics, and his contributions to this and many other investigations were invaluable. We remember and thank our colleague. He will be missed.
}

Lorin K. Roskos

RoskosL@medimmune.com

1 MedImmune LLC, South San Francisco, CA, USA

2 MedImmune LLC, One MedImmune Way, Gaithersburg, MD 20878, USA 


\section{Key Points}

Benralizumab is a targeted therapy approved as add-on maintenance treatment for patients aged 12 years and older with uncontrolled asthma and inflammation associated with eosinophils, a type of white blood cell.

Analysis of pooled pharmacokinetic (PK) data of benralizumab from nine phase I-III clinical trials demonstrated that the PK of benralizumab were consistently dose-proportional across a dosage range of $0.03-3 \mathrm{mg} / \mathrm{kg}$ intravenously and 2-200 $\mathrm{mg}$ subcutaneously every 4 weeks or every 8 weeks (first three doses every 4 weeks). The elimination half-life of benralizumab was approximately 15.5 days for patients with asthma.

Body weight and the presence of antidrug antibodies were the only variables that had an impact on the PK of benralizumab.

\section{Introduction}

Eosinophilic inflammation, an important element of asthma pathogenesis, is associated with increased disease severity and exacerbations, decreased lung function, and increased mortality for patients with asthma [1-4]. Benralizumab is an interleukin-5 receptor (IL-5R) alpha-directed cytolytic monoclonal antibody (mAb) that depletes eosinophils by enhanced antibody-dependent cell-mediated cytotoxicity [5]. It was recently approved as add-on maintenance treatment for patients with severe asthma aged 12 years and older and with an eosinophilic phenotype [6-8].

Pharmacokinetic (PK) and blood eosinophil count data from early stage clinical studies were modeled to facilitate selection of optimal dose levels and dosing schedule of benralizumab for a phase IIb proof-of-concept study for adult patients with severe asthma $[9,10]$. Subsequently, two dosing regimens of benralizumab $30 \mathrm{mg}$ (every 4 weeks, or every 4 weeks for the first three doses followed by every 8 weeks) were selected for the following phase III trials: SIROCCO [11] and CALIMA [12], which evaluated the effect of benralizumab on the rate of annual asthma exacerbation; ZONDA [13], an oral corticosteroid (OCS) reduction study; and BISE [14], a pulmonary function study. SIROCCO and CALIMA reported that benralizumab $30 \mathrm{mg}$ every 4 weeks or every 8 weeks significantly reduced asthma exacerbation rates and increased forced expiratory volume in $1 \mathrm{~s}\left(\mathrm{FEV}_{1}\right)$ for patients with severe asthma receiving high-dosage inhaled corticosteroids/long-acting $\beta_{2}$-agonists with baseline blood eosinophil counts $\geq 300$ cells $/ \mu \mathrm{L}[11,12]$. Subsequent population modeling analyses of pooled data from SIROCCO and CALIMA confirmed that $30 \mathrm{mg}$ every 8 weeks, with an additional dose at week 4 , is the optimal dosage of benralizumab for the treatment of patients with severe asthma [15].

The aims of this investigation were to characterize the PK of benralizumab in adults and adolescents with severe, eosinophilic asthma using a population approach, and to evaluate the potential effects of demographic covariates and concomitant medication use on PK exposure of benralizumab in this population.

\section{Methods}

\subsection{Ethics Approval}

All clinical study protocols and patient consent documents were reviewed by the local Institutional Review Board (IRB), and written IRB approvals were obtained prior to the initiation of each study.

All clinical studies were conducted in accordance with the ethical principles described in the Declaration of Helsinki, the International Conference on Harmonisation Guidance for Good Clinical Practice, any applicable regulatory requirements, and any conditions required by a regulatory authority and/or IRB.

\subsection{Study Population}

Five phase I and II clinical studies (NCT00512486 [16], NCT00659659 [17], NCT00768079 [18], NCT00783289 [19], NCT01238861 [9]) were conducted in adult patients with asthma. Four phase III studies (SIROCCO [NCT01928771] [11], CALIMA [NCT01914757] [12], BISE [NCT02322775] [14], and ZONDA [NCT02075255] [13]) were conducted in adults and adolescents with severe asthma.

\subsection{Dosing and Sampling Schedule}

Patients with asthma received either intravenous or subcutaneous benralizumab. In phase I and II studies, single doses of $0.0003-3 \mathrm{mg} / \mathrm{kg}$ were administered by intravenous infusion. Subcutaneous dosages ranging from 2 to $200 \mathrm{mg}$ were administered every 4 weeks or every 8 weeks. In the phase III studies, benralizumab was administered at $30 \mathrm{mg}$ subcutaneously every 4 weeks, or $30 \mathrm{mg}$ subcutaneously every 8 weeks. Table 1 lists the study designs, number of patients, and PK sampling schedules. 
Table 1 Summary of clinical studies included in the population pharmacokinetic analysis

\begin{tabular}{|c|c|c|c|c|c|c|}
\hline Study number & $\begin{array}{l}\text { Study type and } \\
\text { design }\end{array}$ & Study population & $\begin{array}{l}\text { Dosage(s) of } \\
\text { benralizumab }\end{array}$ & Route & $\begin{array}{l}\text { Frequency of } \\
\text { administration }\end{array}$ & Overall objectives \\
\hline NCT00512486 [16] & Phase I; OL/DE & $\begin{array}{l}\mathrm{M} \text { and } \mathrm{F} \text {; } \\
18-45 \text { years of } \\
\text { age; mild atopic } \\
\text { asthma; } 44 \mathrm{RP}\end{array}$ & $\begin{array}{l}0.03,0.1,0.3,1.0 \\
3.0,0.003 \text {, and } \\
0.0003 \mathrm{mg} / \mathrm{kg}\end{array}$ & IV & Single dose & Safety \\
\hline NCT00659659 [17] & $\begin{array}{l}\text { Phase I; RD/DB/ } \\
\text { PC/DE }\end{array}$ & $\begin{array}{l}\mathrm{M} \text { and F; } \\
18-65 \text { years } \\
\text { of age; } \\
\text { asthma; } \geq 2.5 \% \\
\text { of eosinophils in } \\
\text { sputum; } 27 \mathrm{RP}\end{array}$ & $\begin{array}{l}1.0 \mathrm{mg} / \mathrm{kg} \\
100 \text { and } 200 \mathrm{mg}\end{array}$ & $\begin{array}{l}\text { IV } \\
\text { SC }\end{array}$ & $\begin{array}{l}\text { Single dose } \\
\text { Q4W for } 8 \text { weeks }\end{array}$ & $\begin{array}{l}\text { Safety and } \\
\text { tolerability }\end{array}$ \\
\hline NCT00768079 [18] & $\begin{array}{l}\text { Phase II; RD/DB/ } \\
\text { PC }\end{array}$ & $\begin{array}{l}\mathrm{M} \text { and } \mathrm{F} ; \\
18-60 \text { years of } \\
\text { age; } \geq 2 \text { years of } \\
\text { asthma; asthma } \\
\text { exacerbation } \\
\text { requiring urgent } \\
\text { care in the year } \\
\text { prior to screening; } \\
110 \mathrm{RP}\end{array}$ & 0.3 or $1.0 \mathrm{mg} / \mathrm{kg}$ & IV & Single dose & Safety and efficacy \\
\hline NCT00783289 [19] & $\begin{array}{l}\text { Phase II; RD/DB/ } \\
\text { PC/DE }\end{array}$ & $\begin{array}{c}\mathrm{M} \text { and } \mathrm{F} ; 18-80 \\
\text { years of age; } \\
\text { asthma; } 25 \mathrm{RP}\end{array}$ & 25,100 , or $200 \mathrm{mg}$ & $\mathrm{SC}$ & Q4W for 8 weeks & $\begin{array}{l}\text { Safety and } \\
\text { tolerability }\end{array}$ \\
\hline NCT01238861 [9] & $\begin{array}{l}\text { Phase II; RD/DB/ } \\
\text { PC/DR }\end{array}$ & $\begin{array}{l}\mathrm{M} \text { and F; } \\
18-75 \text { years of } \\
\text { age; asthma; } \\
\text { medium- or } \\
\text { high-dosage ICS/ } \\
\text { LABA; 609 RP }\end{array}$ & 2,20 , or $100 \mathrm{mg}$ & $\mathrm{SC}$ & $\begin{array}{l}\text { Q4W for } 8 \text { weeks, } \\
\text { then Q8W for } \\
32 \text { weeks }\end{array}$ & Safety and efficacy \\
\hline $\begin{array}{l}\text { SIROCCO } \\
\text { (NCT01928771) } \\
{[11]}\end{array}$ & $\begin{array}{l}\text { Phase III; RD/DB/ } \\
\text { PC }\end{array}$ & $\begin{array}{l}\mathrm{M} \text { and F; } \\
\text { 12-75 years of } \\
\text { age; uncontrolled } \\
\text { asthma; high-dos- } \\
\text { age ICS/LABA; } \\
1205 \text { RP }\end{array}$ & $\begin{array}{l}30 \mathrm{mg} \\
30 \mathrm{mg}\end{array}$ & $\begin{array}{l}\text { SC } \\
\text { SC }\end{array}$ & $\begin{array}{l}\text { Q4W for } 44 \text { weeks } \\
\text { Q4W for } 8 \text { weeks, } \\
\text { then Q8W for } \\
32 \text { weeks }\end{array}$ & Safety and efficacy \\
\hline $\begin{array}{l}\text { CALIMA } \\
\text { (NCT01914757) } \\
{[12]}\end{array}$ & $\begin{array}{l}\text { Phase III; RD/DB/ } \\
\text { PC }\end{array}$ & $\begin{array}{l}\mathrm{M} \text { and F; } \\
\text { 12-75 years of } \\
\text { age; uncontrolled } \\
\text { asthma; mid- or } \\
\text { high-dosage ICS/ } \\
\text { LABA; 1306 RP }\end{array}$ & $\begin{array}{l}30 \mathrm{mg} \\
30 \mathrm{mg}\end{array}$ & $\begin{array}{l}\text { SC } \\
\text { SC }\end{array}$ & $\begin{array}{l}\text { Q4W for } 52 \text { weeks } \\
\text { Q4W for } 8 \text { weeks, } \\
\text { then Q8W for } \\
40 \text { weeks }\end{array}$ & Safety and efficacy \\
\hline $\begin{array}{l}\text { ZONDA } \\
\quad(\text { NCT02075255) } \\
{[13]}\end{array}$ & $\begin{array}{l}\text { Phase III; RD/DB/ } \\
\text { PC }\end{array}$ & $\begin{array}{l}\mathrm{M} \text { and F; } \\
\text { 18-75 years of } \\
\text { age; uncontrolled } \\
\text { asthma; high- } \\
\text { dosage ICS/LABA } \\
\text { and long-term } \\
\text { oral corticosteroid } \\
\text { therapy; } 220 \mathrm{RP}\end{array}$ & $\begin{array}{l}30 \mathrm{mg} \\
30 \mathrm{mg}\end{array}$ & $\begin{array}{l}\text { SC } \\
\text { SC }\end{array}$ & $\begin{array}{l}\text { Q4W for } 24 \text { weeks } \\
\text { Q4W for } 8 \text { weeks, } \\
\text { then Q8W for } \\
16 \text { weeks }\end{array}$ & Safety and efficacy \\
\hline $\begin{array}{l}\text { BISE } \\
\quad(\mathrm{NCT} 02322775) \\
{[14]}\end{array}$ & $\begin{array}{l}\text { Phase III; RD/DB/ } \\
\text { PC }\end{array}$ & $\begin{array}{l}\mathrm{M} \text { and F; } \\
\text { 18-75 years of } \\
\text { age; mild to mod- } \\
\text { erate persistent } \\
\text { asthma; } 211 \mathrm{RP}\end{array}$ & $30 \mathrm{mg}$ & $\mathrm{SC}$ & $\begin{array}{l}3 \text { doses at weeks } 0 \text {, } \\
4 \text {, and } 8\end{array}$ & Safety and efficacy \\
\hline
\end{tabular}

$D B$ double-blind, $D E$ dose escalation, $D R$ dose ranging, $F$ female, $I C S$ inhaled corticosteroids, $I V$ intravenous, $L A B A$ long-acting $\beta_{2}$-agonist, $M$ male, $O L$ open label, $P C$ placebo-controlled, $Q 4 W$ every 4 weeks, $Q 8 W$ every 8 weeks, $R D$ randomized, $R P$ randomized patients, $S C$ subcutaneous 


\subsection{Bioanalysis}

We determined plasma or serum concentrations of benralizumab using validated immunoassays. Noncompeting anti-benralizumab idiotype antibodies were used as capturing and detecting reagents. For study NCT00512486, we measured benralizumab plasma concentrations with a validated enzyme-linked immunoassay method with a lower limit of quantification (LLOQ) of $60 \mathrm{ng} / \mathrm{mL}$. For the other studies, benralizumab concentrations in serum (or plasma for study NCT00659659) were determined using a validated electrochemiluminescent sandwich immunoassay that employed Meso Scale Discovery (Rockville, MD, USA) technology, with an LLOQ of $3.86 \mathrm{ng} / \mathrm{mL}$.

\subsection{Pharmacokinetic (PK) Data Analysis}

\subsubsection{Data Handling and Exclusions}

The PK and demographic covariate data from each study were formatted into derived population analysis datasets using SAS 9.3 (SAS Institute Inc, Cary, NC, USA). We excluded PK concentration outliers with no mechanistic explanation for their deviations from the analysis (a priori outliers). Outliers based on the population PK model analysis (a posteriori outliers) were evaluated using conditional weighted residuals (CWRES) and individual weighted residuals (IWRES) [20]. Observations with $|C W R E S|>6$ or IIWRESI > 6 were flagged as outliers.

We evaluated the influence of a posteriori outliers by comparing estimates of the key model parameters (e.g. systemic clearance [CL]) from model fitting on data with and without outliers. The outliers were considered influential if key parameter estimates differed by $>15 \%$. If outliers were influential, we performed subsequent model development with and without outlying observations.

\subsubsection{Data Analysis Plan}

The population PK analysis proceeded in stages that consisted of adding new data (e.g. by study or administration route) to evaluate changes in PK parameter estimates and ensure adequate pooling of data. First, PK data from early stage studies with intravenous benralizumab were modeled. We then added PK data corresponding to subcutaneous administration for the assessment of absorption rate and absolute bioavailability. Data from the SIROCCO, CALIMA, and BISE studies were also included in the metaanalysis and base model development. A demographic covariate analysis was subsequently performed. Next, we used PK data from ZONDA, a phase III OCS-reduction study, for external validation of the final population PK model. Finally, ZONDA data were integrated into the metaanalysis dataset for re-estimation of the structure and variance parameters.

\subsubsection{Modeling Methodology}

Population model development and simulation were performed using NONMEM (version 7.3; ICON Development Solutions, Hanover, MD, USA) [20]. The planned method of estimating parameters was the first-order conditional estimation with interaction (FOCEI). We generated data summaries and graphical representations using SAS version 9.3, Splus version 8.2 (TIBCO, Palo Alto, CA), or R version 3.1.2 (The R Foundation for Statistical Computing, Vienna, Austria).

Model development was based on successful minimization and assessment of standard goodness-of-fit (GOF) plots. In addition, we assessed the stability of the models throughout the development process. The covariance matrix of estimates was inspected to verify that extreme pairwise correlations $(p>0.95)$ of the parameter estimates were not encountered. During model development, if convergence or covariance estimation problems occurred, ad hoc NONMEM runs were performed to evaluate the nature of the ill-conditioning.

\subsubsection{Structural PK Model}

Benralizumab PK data were initially fitted using a twocompartment model with first-order absorption from the subcutaneous dosing site and first-order elimination from the central compartment, based on a previous population PK analysis of data from early phase studies [10]. The model was parameterized using bioavailability $\left(F_{1}\right)$ fraction, an apparent absorption rate constant $\left(k_{\mathrm{a}}\right)$, systemic $\mathrm{CL}$, central volume of distribution $\left(V_{\mathrm{c}}\right)$, intercompartmental $\mathrm{CL}(Q)$, and peripheral volume of distribution $\left(V_{\mathrm{p}}\right)$ (Fig. 1).

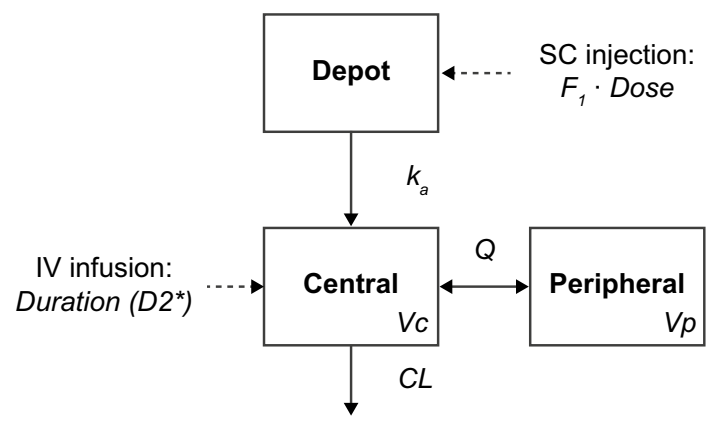

Fig. 1 Schematic of the population PK model structure. $C L$ clearance, $F_{l}$ bioavailability, $I V$ intravenous, $k_{\mathrm{a}}$ absorption rate constant, $P K$ pharmacokinetic, $Q$ intercompartmental clearance, $S C$ subcutaneous, $V_{\mathrm{c}}$ central volume of distribution, $V_{\mathrm{p}}$ peripheral volume of distribution 
Log-based parameterization is a modification for the typical individual parameter $\left(\theta^{P}\right)$ and is used to facilitate $\mathrm{MU}$ processing in NONMEM, which increases the computational efficiency of estimation. The equation for a PK parameter $P$, based on the model described above, is as shown in Eq. (1):

$\ln \left(P_{i}\right)=\theta^{P}+\eta_{i}^{P}$,

where $i$ indexes the $i$ th patient, and $\eta_{i}^{P}$ is the patient-specific random effect for $P . \eta_{i}^{P}$ was assumed to be normally distributed, with a mean of zero and a variance of $\omega_{P}{ }^{2}$ [i.e. $\left.\eta_{i}^{P} \sim N\left(0, \omega_{P}^{2}\right)\right]$. Estimated $\theta^{P}$ values were back-transformed to the original scale to facilitate interpretability.

\subsubsection{Stochastic PK Model}

The population PK base model consisted of the structural model, between-patient variability (BPV), and residual error model. Interoccasion variability (IOV) was also evaluated. We performed population analysis to determine a parsimonious and stable model that described the data adequately.

The BPV model is described in Eq. (1). The initial residual error model contained a proportional component and an additive component (Eq. 2):

$C(t)_{i j}=\hat{C}(t)_{i j} \cdot\left(1+\varepsilon_{p i j}\right)+\varepsilon_{a i j}$

where $C(t)_{i j}$ is the observed serum concentration and $\hat{C}(t)_{i j}$ is the model-predicted serum concentration for sample $j$ of individual $i$, and $\varepsilon_{p i j}$ and $\varepsilon_{a i j}$ are normally distributed residual random errors with a mean of 0 and variances of $\sigma_{1}^{2}$ and $\sigma_{2}^{2}$, respectively.

\subsubsection{Covariate Model-Building Procedure}

We selected demographic covariates based on clinical judgment, mechanistic plausibility, and prior knowledge. PK parameter-covariate relationships were initially examined graphically to identify any potential relationships to be assessed in subsequent modeling.

A full-model approach was employed by simultaneously including into the base PK model all covariates demonstrating a trend in their empirical Bayes estimates of the random effects $\eta$. We modeled the relationship between continuous covariates and PK parameters using power functions, with the covariate $X$ normalized by a reference value $X_{\text {ref }}(70 \mathrm{~kg}$ for body weight and approximate median for other covariates). The continuous covariate effect on a PK parameter $P$ with log-based parameterization is presented in Eq. (3):

$$
\ln P=\theta^{P}+\theta^{X}\left(\ln X-\ln X_{\text {ref }}\right) \text {. }
$$

The categorical covariates were modeled using fractional change functions of the covariate factor (Eq. 4, with logbased parameterization):

$\ln P=\theta^{P}+\theta^{Y} \cdot Y$, where $\theta^{Y}$ represents the logarithm of the fractional change to the PK parameter $P$ when factor $Y=1$.

The effects of injection site (arm, stomach, or thigh) and antidrug antibody (ADA) status could not be evaluated by covariate $\eta$ plots and were evaluated in an ad hoc fashion following formal covariate analysis.

\subsubsection{Finalization of the Population PK Model}

We developed the final model by incorporating the effect of relevant covariates on key structural model parameters of the base model.

Because of the extensive PK data, long model run times, and the limitation of the backward elimination procedure only providing one specified path through the model space, the Wald's Approximation Method (WAM) [21] was used to identify a subset of reduced PK models relative to the PK full model. The WAM procedure ranked all $2^{k}$ possible submodels derived from the presence or absence of $k$ covariate parameters in the full model. The WAM algorithm approximates the log-likelihood surface by a quadratic equation in the covariate effects based on the estimates and asymptotic variance-covariance matrix of the estimates from the full model fit. Typically, maximizing Schwarz's Bayesian Criterion is used as a penalty to rank all $2^{k}$ possible models. In this case, the penalty of 10.83 corresponding to a $p$ value cut-off of 0.001 from a Chi-square distribution with 1 degree of freedom was used as a penalty to the likelihood ratio test. The final parsimonious model was selected based on NONMEM rankings.

Assessment of the GOF plots, visual predictive checks (VPCs), and external model validation were conducted to evaluate the performance of the final PK model.

\section{Results}

\subsection{Data Summary}

A total of 3533 patients with asthma were included in the initial dataset (excluding ZONDA). PK data from 1227 patients who received placebo, and samples obtained prior to the first dose of benralizumab, were excluded from the analysis. Because of the low and variable PK concentrations in patients with asthma receiving benralizumab $2 \mathrm{mg}$ subcutaneously in study NCT01238861, the 589 samples from these 81 patients were excluded from population modeling. Missing PK concentrations from 17 patients and 75 PK concentrations with unrealistic values or unclear dosing records were also excluded. 
The initial population PK model (excluding ZONDA) was supported by 14,106 quantifiable benralizumab concentrations from 2174 patients with asthma. The majority of patients received a subcutaneous injection at $30 \mathrm{mg}(80 \%)$ or $100 \mathrm{mg}(11 \%)$. Pivotal phase III studies (SIROCCO, CALIMA) contributed the most observations, followed by the phase IIb study NCT01238861. In addition, ZONDA contributed 832 quantifiable serum benralizumab concentrations from 143 patients for external model validation.

The baseline continuous and categorical covariates that were investigated in the population PK model included body weight, age, age group (adult or adolescent), race, smoking status, hepatic markers (alkaline phosphatase [ALP], alanine aminotransferase [ALT], aspartate aminotransferase [AST] and total bilirubin [TBL]), creatine CL (CRCL), albumin, immunogenicity status, and concomitant use of montelukast, paracetamol, proton pump inhibitors, macrolides, or theophylline/aminophylline (Tables 2 and 3).

\subsection{Structure PK Model Development}

Table 4 presents the key steps in the development of the benralizumab population PK model. Model development was initiated with the analysis of intravenous data. The iterative two-stage (ITS)/stochastic approximation expectation maximization (SAEM)/importance sampling (IMP) methods, as implemented in NONMEM, were adopted, and the PK concentration data were log-transformed to facilitate model development. A log-normal residual error structure was used to increase the influence of lesser concentrations on the estimates.

The PK model was subsequently expanded to incorporate the subcutaneous route of administration, which was adequately described by a first-order absorption process. Exponential parameterization performed slightly better than a logit transformation for absolute bioavailability $\left(F_{1}\right)$. The estimated $F_{1}$ and BPV of $F_{1}$ for study NCT01238861 were different from the other studies. In addition, the variance of residual error $\left(\sigma^{2}\right)$ was different for early stage studies (phase I-IIa, studies NCT00512486, NCT00659659, NCT00768079 and NCT00783289), phase IIb (NCT01238861), and phase III studies (SIROCCO, CALIMA, and BISE).

\subsection{Covariate Analysis}

Body weight was identified as a relevant covariate, with significant effects on CL, $V_{\mathrm{c}}$, and $V_{\mathrm{p}}$ (Model 6, Table 4). In addition, the inclusion of ADA status on $C L$ resulted in a $>4000$-unit reduction in objective function $(\mathrm{OBJ})$ value (Model 7, Table 4).

The effects of other covariates were evaluated using plots of empirical Bayes estimates (i.e. ETA plots). No real trends in the ETA plots were noted, except a modest correlation between $\eta_{\mathrm{CL}}$ and CRCL. Using the WAM algorithm, the effect of sex, race-Asian, and race-black on CL was $<10 \%$. The effect of race-other on CL was $19 \%$, but the $90 \%$ confidence interval precluded a meaningful effect. These covariate effects were also considered nonmeaningful for $V_{c}$. The statistical detection of such nonmeaningful effects likely stemmed from the large sample size in the dataset.

The effect of CRCL on CL was statistically significant; an estimate of 0 was not precluded. There was a general trend of increasing effect on CL with greater CRCL. However, the apparent correlation of CRCL and benralizumab CL could be an artifact as both were influenced by body weight (heavier patients tended to have greater CRCL and $\mathrm{CL}$ ). A posterior ad hoc analysis confirmed that renal function (estimated glomerular filtration rate [eGFR]) did not influence benralizumab CL.

Hepatic function markers (ALP, ALT, AST, and TBL), concomitant medications, or baseline eosinophil count had no impact on the PK of benralizumab.

\subsection{External Model Validation}

The final model was used to predict benralizumab PK profiles from ZONDA. The model-predicted PK exposures, represented by $90 \%$ percentile intervals (PIs), were compared with observed serum concentrations of benralizumab in ZONDA. Figure 2 presents results of the VPCs, grouped by regimen and quantile of body weight. Observed PK profiles in ZONDA were mostly within the PIs across all weight ranges, indicating that the model was adequate in predicting ZONDA benralizumab exposures.

\subsection{Final Updated Population PK Model}

ZONDA data were appended to the analysis dataset that contained PK data from three phase III studies (SIROCCO, CALIMA, and BISE) and five early phase studies. The PK model was refitted to the pooled 14,918 observations for 2317 patients from all nine clinical studies. Table 5 presents the structure and variance parameter estimates. A VPC was performed for the final updated model, which adequately captured the population concentration-time profile of benralizumab (Fig. 3).

Figure 4 illustrates the effects of body weight and ADA on the PK of benralizumab. Benralizumab CL and volumes of distribution were greater for patients with greater body weight. The presence of ADA was associated with elevated $\mathrm{CL}$ of benralizumab.

During model development, CRCL had a statistically significant effect on CL. The renal function classification based on the CRCL and eGFR values was performed according to the FDA Guidance for Industry [22]. Despite the apparent trend of increasing benralizumab CL with greater CRCL (Fig. 5a), there was no correlation of CL with eGFR 


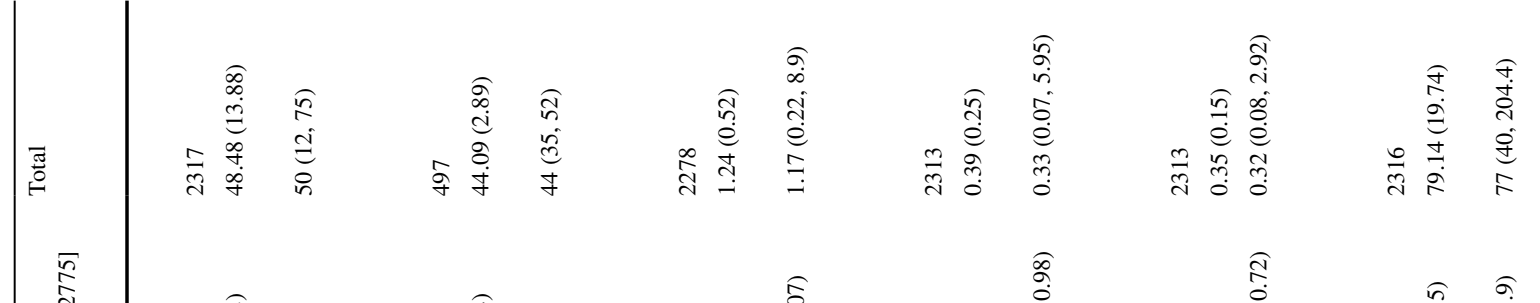

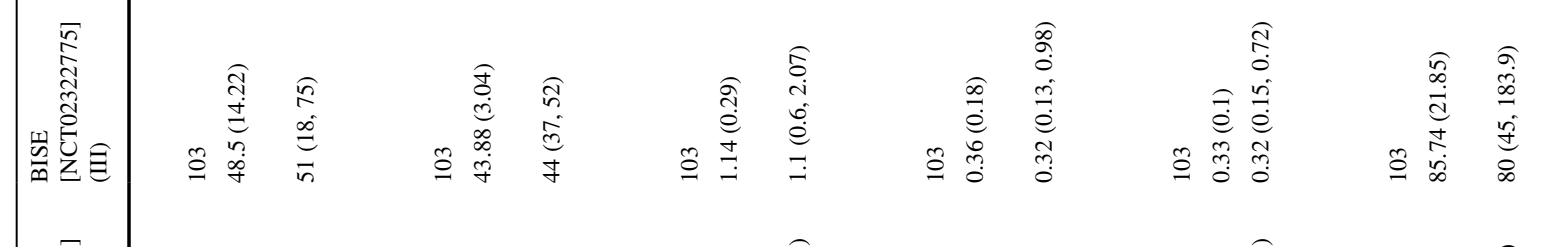

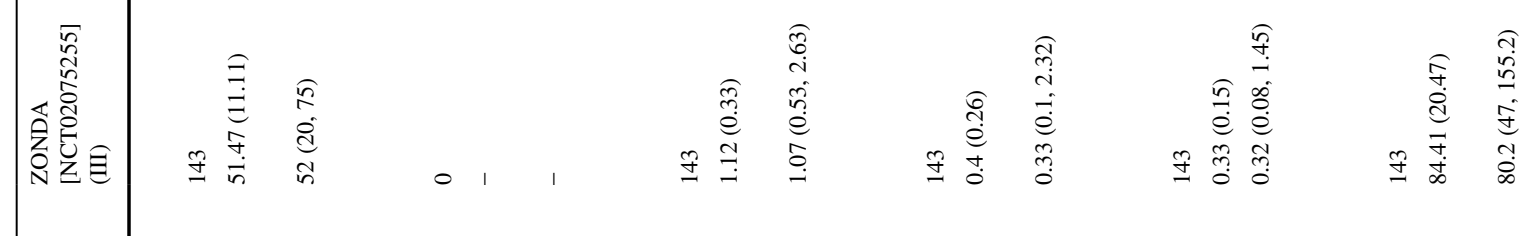

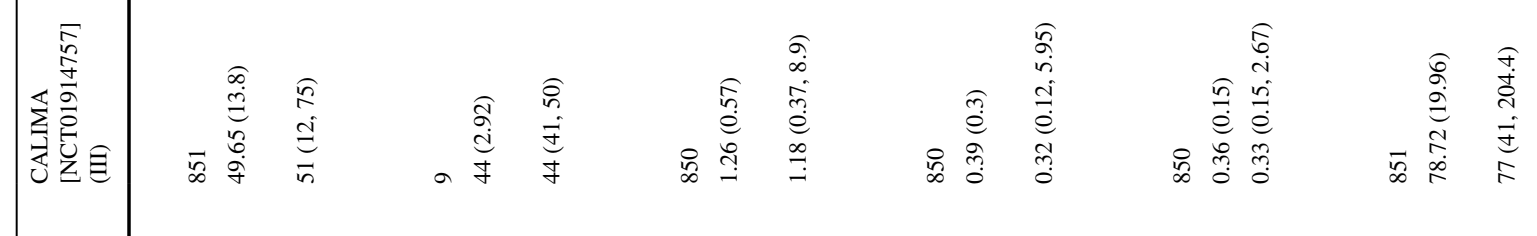

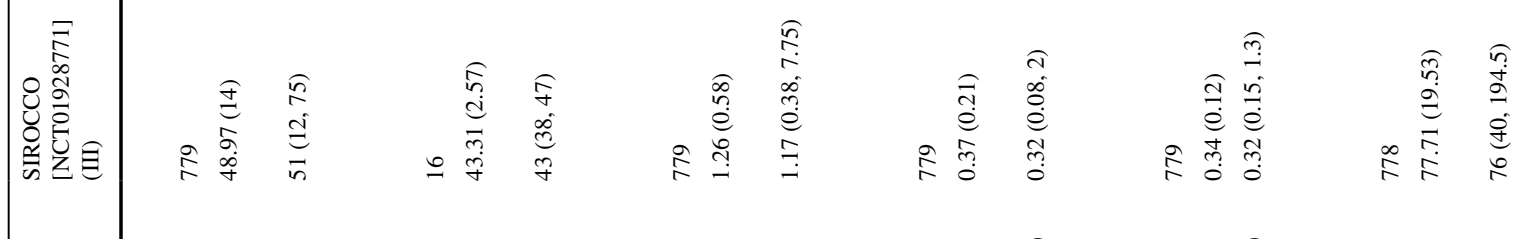

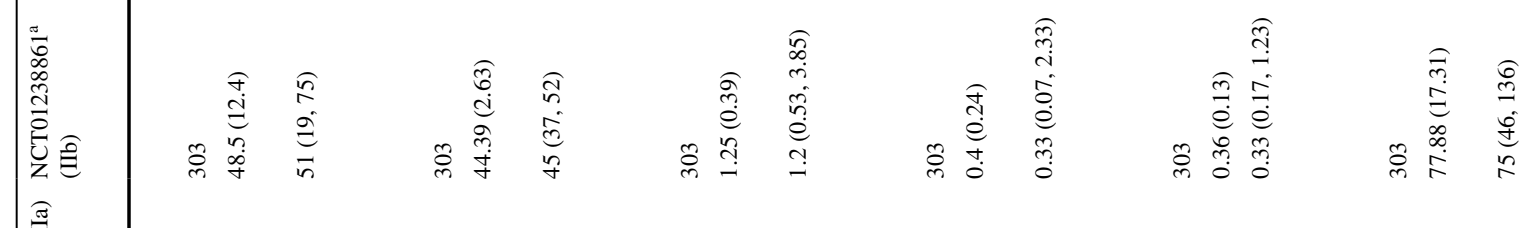

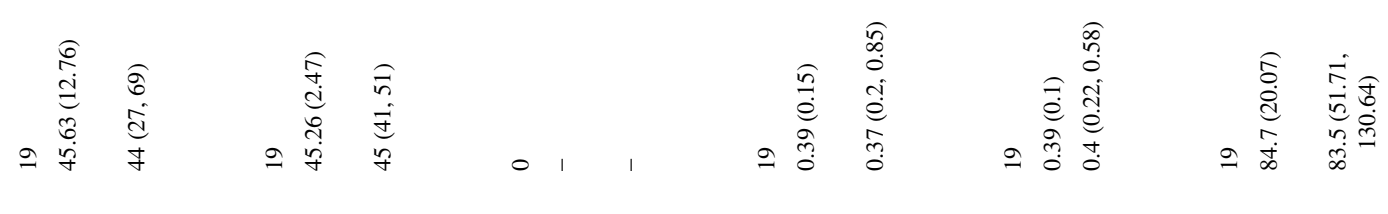

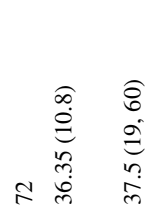

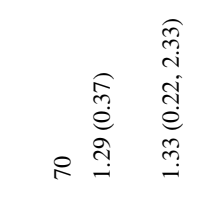

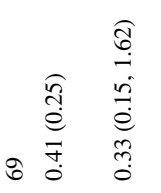

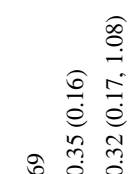

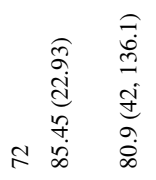

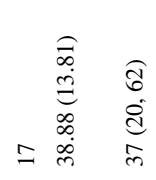

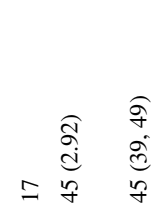

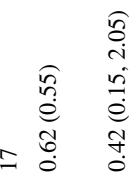

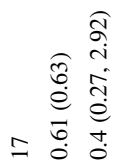

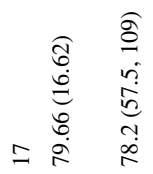

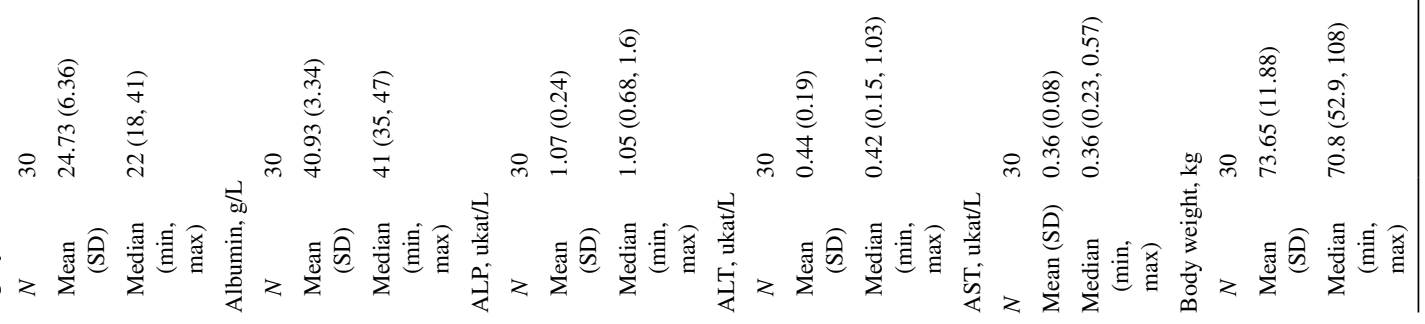




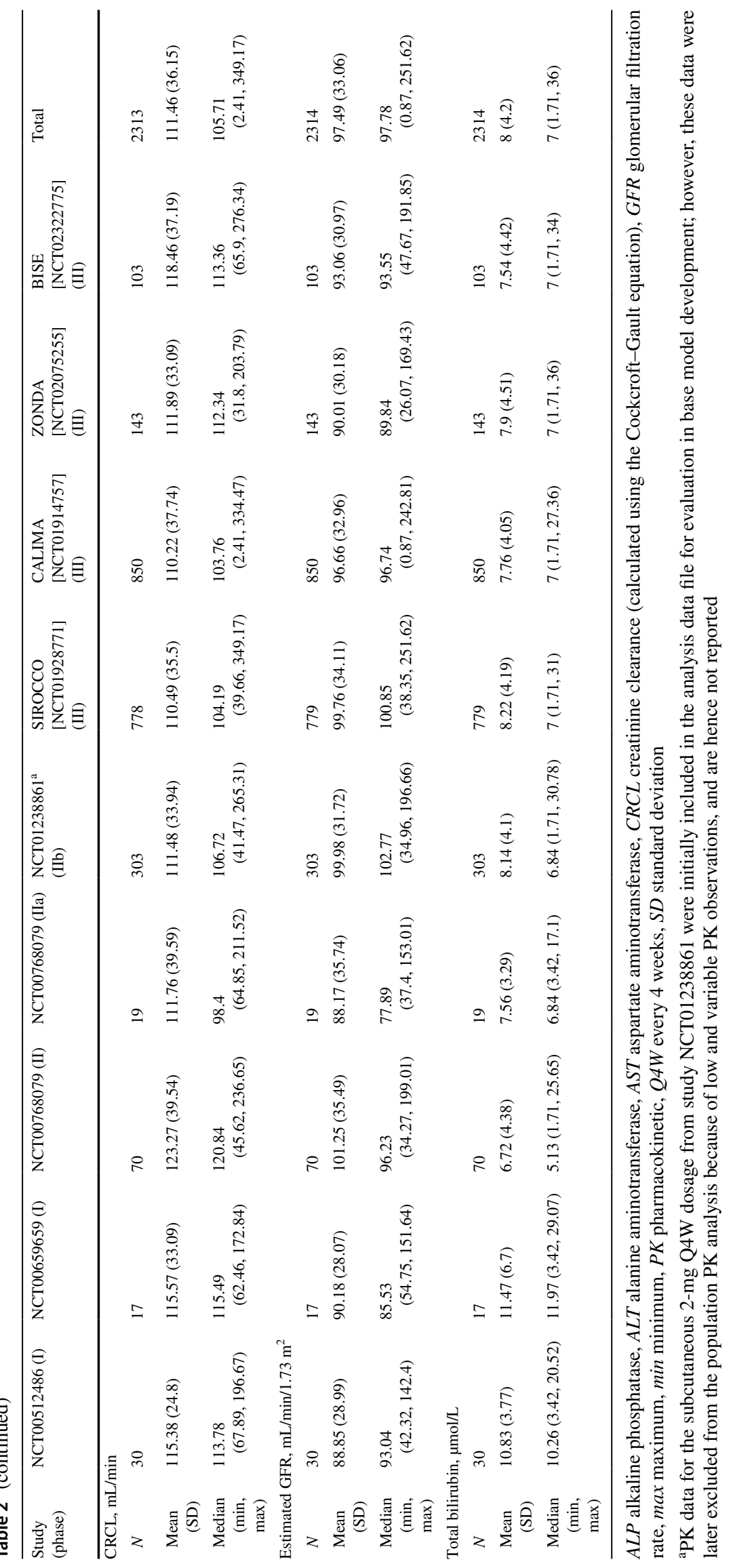




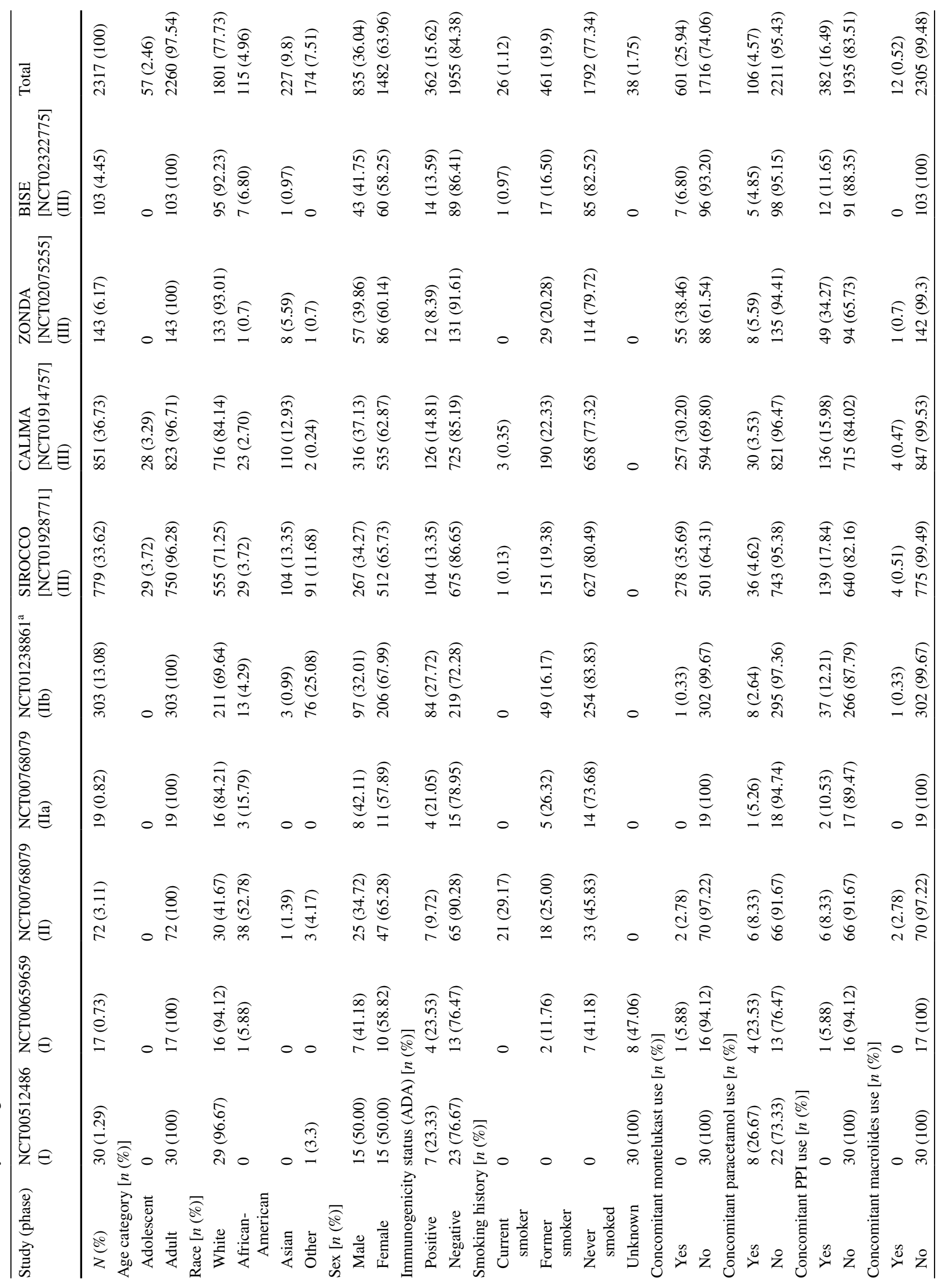


(Fig. 5b). Baseline blood eosinophil count had no effect on benralizumab CL. Figure 5c shows a box plot comparing CL for patients with asthma by baseline blood eosinophil counts $(<150,150-299,300-449$, and $>450$ cells $/ \mu \mathrm{L})$.

Subcutaneous benralizumab was administrated exclusively in the upper arm in many early stage studies; however, in later stage studies, benralizumab was also administered in the abdomen and thigh. An ad hoc analysis demonstrated no clinically relevant effect of anatomical injection site on benralizumab bioavailability.

\section{Discussion}

Treatment with benralizumab, a potent anti-eosinophil mAb, leads to nearly complete depletion of blood and airway eosinophils for patients with mild to severe asthma following single or repeated dosing $[5,6,8]$. The phase III program of benralizumab demonstrated a significant and clinically relevant reduction in asthma exacerbations, improvement in lung functions, and reduced asthma symptoms and OCS use for patients with severe asthma compared with placebo. Benralizumab is approved as an add-on maintenance treatment for patients $\geq 12$ years of age with severe asthma and an eosinophilic phenotype [6-8]. The PK of benralizumab have been demonstrated to be dose-proportional at dosages of $0.03-3 \mathrm{mg} / \mathrm{kg}$ [16].

The PK of benralizumab were evaluated in nine clinical studies for adults and adolescents with severe asthma. Benralizumab dosage, dosing intervals, administration routes, and treatment durations differed across studies. The weight-based dosing method was used in early stage studies, whereas fixed subcutaneous doses of benralizumab were administered to patients in phase II and III studies. In addition, except for in the first-in-human study NCT00512486, the PK sampling schedule was limited or sparse (Table 1). To fully characterize the PK properties of benralizumab and to assess the clinical relevance of demographic covariate effects, PK data from these studies were pooled for a population meta-analysis.

A total of 14,983 quantifiable PK observations from 2317 benralizumab-treated patients were included in the population analysis dataset. Data from 81 patients who received benralizumab 2 mg every 8 weeks in study NCT01238861 (3.4\% of all benralizumab-treated patients) were excluded as the majority of observed trough PK concentrations were below the limit of quantification (BLQ), and the dosage was 15 -fold less than the 30-mg therapeutic dosage evaluated in the phase III program. In addition, as $<10 \%$ of data records were BLQ, imputing methods for BLQ observations were not implemented [23]. Of four phase III studies in the population modeling dataset, ZONDA was the last to complete. Therefore, PK data from ZONDA were used for model external validation [24]. 
Table 4 Key model development steps

\begin{tabular}{|c|c|c|c|c|c|}
\hline Model no. & Description & Dataset & OBJ & $\Delta \mathrm{OBJ}$ & Comparator \\
\hline 1 & Two-compartment model & IV data only & -878.82 & NA & NA \\
\hline 2 & Two-compartment PK, first-order SC absorption & $\mathrm{IV}+\mathrm{SC}^{\mathrm{a}}$ & -212.22 & NA & NA \\
\hline 3 & $\begin{array}{l}\text { Two-compartment PK, first-order SC absorption, } \\
\text { separated } F_{1} \text { for the phase IIb study NCT01238861 }\end{array}$ & $\mathrm{IV}+\mathrm{SC}^{\mathrm{a}}$ & -455.42 & -243.20 & Model 2 \\
\hline 4 & $\begin{array}{l}\text { Separated } F_{1} \text { and residual error for the phase IIb study } \\
\text { NCT01238861 }\end{array}$ & $\mathrm{IV}+\mathrm{SC}^{\mathrm{a}}$ & -613.09 & -157.67 & Model 3 \\
\hline 5 & $\begin{array}{l}\text { Further separated residual error for phase III studies, } \\
\text { base model }\end{array}$ & $\mathrm{IV}+\mathrm{SC}^{\mathrm{a}}$ & -834.038 & -215.66 & Model 4 \\
\hline 6 & Base model + body weight effects on CL, $V_{\mathrm{c}}$, and $V_{\mathrm{p}}$ & $\mathrm{IV}+\mathrm{SC}^{\mathrm{a}}$ & -1324.92 & -496.17 & Model 5 \\
\hline 7 & Added ADA effect on CL & $\mathrm{IV}+\mathrm{SC}^{\mathrm{a}}$ & -5547.03 & -4222.1 & Model 6 \\
\hline 8 & Fixed $\operatorname{IIV}(Q)=0.008$; final model & $\mathrm{IV}+\mathrm{SC}^{\mathrm{a}}$ & -5549.28 & 2.25 & Model 7 \\
\hline 9 & Including ZONDA; final updated model & IV + SC (including ZONDA) & -6506.498 & NA & NA \\
\hline
\end{tabular}

$\overline{A D A}$ antidrug antibody, $C L$ clearance, $F_{1}$ bioavailability, $I V$ intravenous, $N A$ not applicable, $O B J$ objective function, $P K$ pharmacokinetics, $S C$ subcutaneous, $V_{\mathrm{c}}$ central volume of distribution, $V_{\mathrm{p}}$ peripheral volume of distribution, $\Delta$ indicates change in

${ }^{a}$ Does not include data from ZONDA

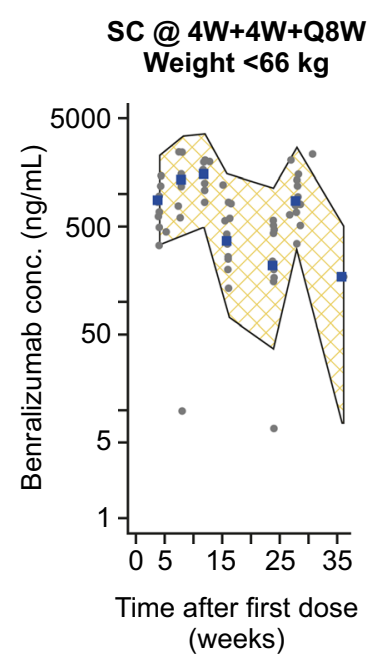

SC Q4W

Weight $<66 \mathrm{~kg}$

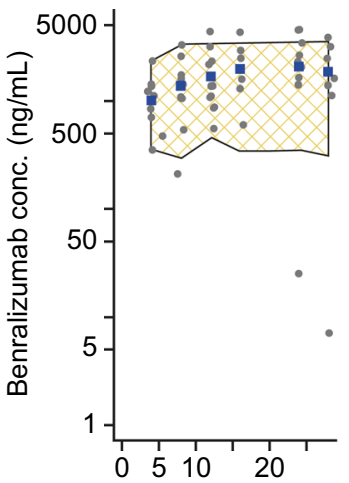

Time after first dose (weeks)
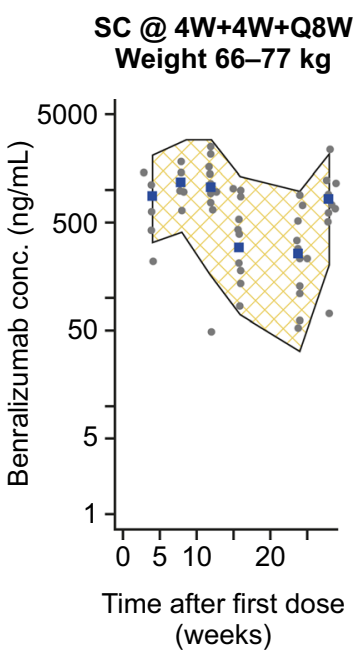

SC Q4W

Weight 66-77 kg

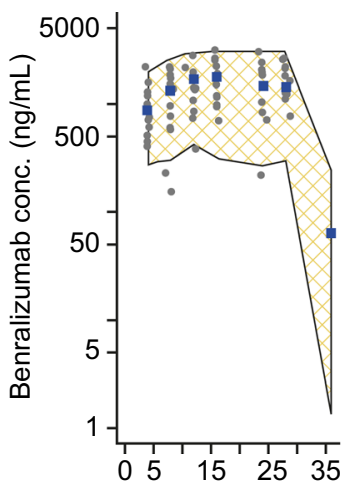

Time after first dose (weeks)

Fig. 2 Model external validation using PK data from study ZONDA. Visual prediction checks, grouped by regimen and body weight quantile. Shaded area represents the $90 \%$ PI of model-predicted PK exposure. Gray points indicate observed serum concentrations of

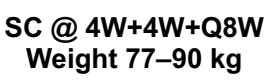

SC @ 4W+4W+Q8W

Weight $>90 \mathrm{~kg}$
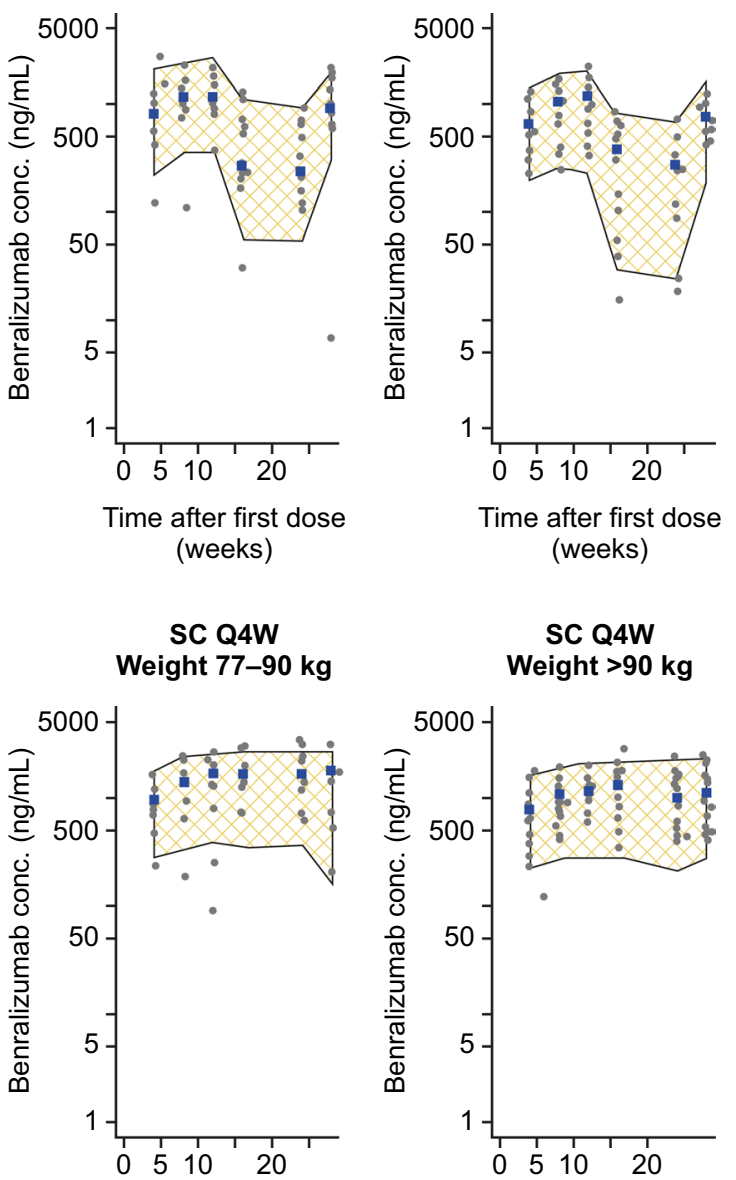

SC Q4W

Weight $77-90 \mathrm{~kg}$

Time after first dose (weeks)

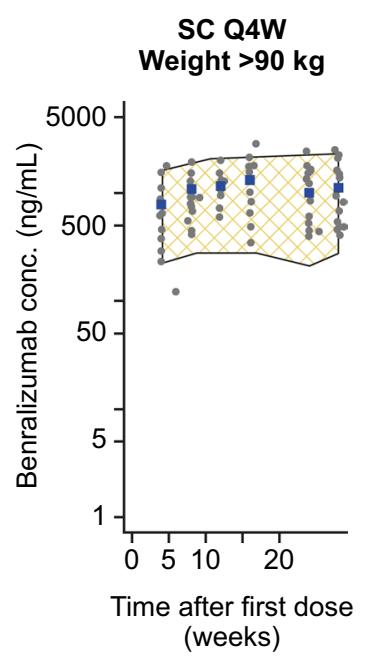

benralizumab in ZONDA, and blue boxes indicate the observed medians. @ $4 W+4 W+Q 8 W$ every 4 weeks for the first three doses, followed by every 8 weeks, Conc. concentration, PI prediction interval, $P K$ pharmacokinetic, $Q 4 W$ every 4 weeks, $S C$ subcutaneous 
Table 5 Pharmacokinetic parameter estimates for the base and final updated models

\begin{tabular}{|c|c|c|c|c|}
\hline \multirow[t]{2}{*}{ Parameter } & \multicolumn{2}{|c|}{ Base model (Model 5) } & \multicolumn{2}{|c|}{$\begin{array}{l}\text { Final updated model } \\
\text { (Model 9) }\end{array}$} \\
\hline & Estimate & $90 \% \mathrm{CI}$ & Estimate & $90 \% \mathrm{CI}$ \\
\hline CL, L/day & 0.357 & $0.341-0.374$ & 0.291 & $0.28-0.302$ \\
\hline Body weight on CL, power & & & 0.807 & $0.751-0.864$ \\
\hline ADAs on CL, fraction & & & 2.24 & $2.18-2.3$ \\
\hline$V_{\mathrm{c}}, \mathrm{L}$ & 3.82 & $3.56-4.10$ & 3.13 & $2.97-3.31$ \\
\hline Body weight on $V_{\mathrm{c}}$, power & & & 0.803 & $0.627-0.979$ \\
\hline$Q, \mathrm{~L} /$ day & 1.46 & $0.899-2.38$ & 0.738 & $0.679-0.803$ \\
\hline Body weight on $Q$, power & & & 0 & - \\
\hline$V_{\mathrm{p}}, \mathrm{L}$ & 2.77 & $2.49-3.09$ & 2.52 & $2.34-2.71$ \\
\hline Body weight on $V_{\mathrm{p}}$, power & & & 0.528 & $0.351-0.706$ \\
\hline$k_{\mathrm{a}}$, half-life; days & 3.35 & $2.76-4.07$ & 3.54 & $3.15-3.99$ \\
\hline$F$ & 0.671 & $0.637-0.707$ & 0.589 & $0.565-0.614$ \\
\hline Change in $F$ with study $\mathrm{CP} 220$, fraction & 0.569 & $0.521-0.622$ & 0.490 & $0.461-0.522$ \\
\hline \multicolumn{5}{|l|}{ IIV } \\
\hline$\eta_{\mathrm{CL}}, \% \mathrm{CV}$ & 29.5 & $27.6-31.3$ & 24.2 & $22.6-25.6$ \\
\hline$\eta_{\mathrm{Vc}}, \% \mathrm{CV}$ & 29.9 & $24.6-34.5$ & 24.4 & $20.7-27.6$ \\
\hline$\eta_{\mathrm{Q}}, \% \mathrm{CV}$ & 132 & $101-157$ & 8.94 & - \\
\hline$\eta_{\mathrm{Vp}}, \% \mathrm{CV}$ & 37.3 & $29.6-43.6$ & 44.7 & $40.5-48.5$ \\
\hline$\eta_{\text {ka (half-life) }} \% \mathrm{CV}$ & 68.1 & $57.6-77.2$ & 83.1 & $75.5-90.1$ \\
\hline$\eta_{\mathrm{F}}, \% \mathrm{CV}$ & 11.9 & $4.19-16.3$ & 17.1 & $13.5-20$ \\
\hline$\eta_{\mathrm{F} \text { (study CP220) }} \% \mathrm{CV}$ & 61.6 & $53.4-68.7$ & 35.0 & $28.8-40.2$ \\
\hline \multicolumn{5}{|l|}{ Residual variability } \\
\hline Proportional error, $\% \mathrm{CV}$ & 28.1 & $26.5-29.7$ & 25.0 & $23.8-26.1$ \\
\hline Proportional error (study CP220), \%CV & 57.9 & $55.5-60.1$ & 54.5 & $52.5-56.3$ \\
\hline $\begin{array}{l}\text { Proportional error (studies SIROCCO, } \\
\left.\text { CALIMA, ZONDA }{ }^{\mathrm{a}}, \mathrm{BISE}\right), \% \mathrm{CV}\end{array}$ & 46.0 & $45.4-46.7$ & 36.7 & $36.2-37.1$ \\
\hline
\end{tabular}

$A D A s$ antidrug antibodies, $C I$ confidence interval, $C L$ clearance, $C V$ coefficient of variation, $F$ bioavailability, $I I V$ interindividual variability, $k_{\mathrm{a}}$ absorption rate constant, $Q$ intercompartmental clearance, $V_{\mathrm{c}}$ central volume of distribution, $V_{\mathrm{p}}$ peripheral volume of distribution

a ZONDA was not included in the base model
Although the FOCEI method, as implemented in NONMEM, was initially planned for the pharmacometrics assessment, expectation maximization (EM) methods were instead used to facilitate PK model development. Given the heterogeneity of data across studies and the sparse PK sampling schedule in late-stage studies, the FOCEI method occasionally led to convergence difficulties. Conversely, the SAEM method in conjunction with IMP proved to be robust and flexible. At each iteration, the Markov Chain Monte Carlo SAEM led toward the maximum of exact likelihood. The OBJ value was obtained by IMP at the final parameter values. The final PK model developed with EM methods (prior to external validation with ZONDA data) was rerun with the FOCEI method, and OBJ values from the two methods were comparable: the OBJ of FOCEI was 0.45 units greater than SAEM/IMP. In this analysis, the reported OBJ and parameter estimates are all based on EM methods.

The PK of benralizumab were dose-proportional across a wide range of dosages investigated in these studies and were adequately described by a two-compartment model with first-order elimination from the central compartment and a first-order absorption process from the subcutaneous dosing site. From population modeling, there was no evidence of an IL-5R-mediated nonlinear elimination pathway because of the rapid depletion of circulating IL-5R-expressing eosinophils following benralizumab administration. In addition, given the slow absorption of immunoglobulin $\mathrm{G}(\mathrm{IgG})$ from the subcutaneous dosing site and the limited PK sampling schedule in phase II and III studies, delayed absorption or logit-transformed bioavailability were not supported by available data.

The absorption of benralizumab was slow following subcutaneous administration, with an estimated absorption half-life of 3.5 days for patients with asthma (Table 5). The estimated absolute bioavailability of benralizumab from population modeling was $59 \%$, which is in line with other approved therapeutic $\mathrm{mAbs}$ and $\mathrm{Fc}$-fusion proteins $[25,26]$. In phase II studies, subcutaneous benralizumab 
IV

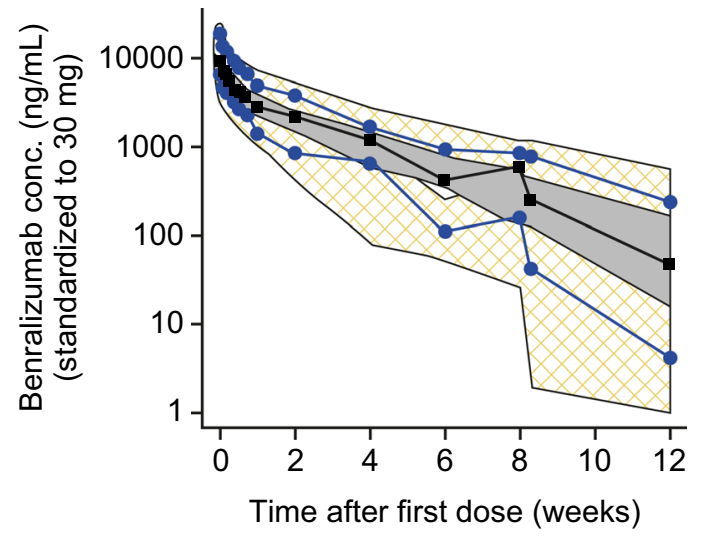

Study 17 Q4W

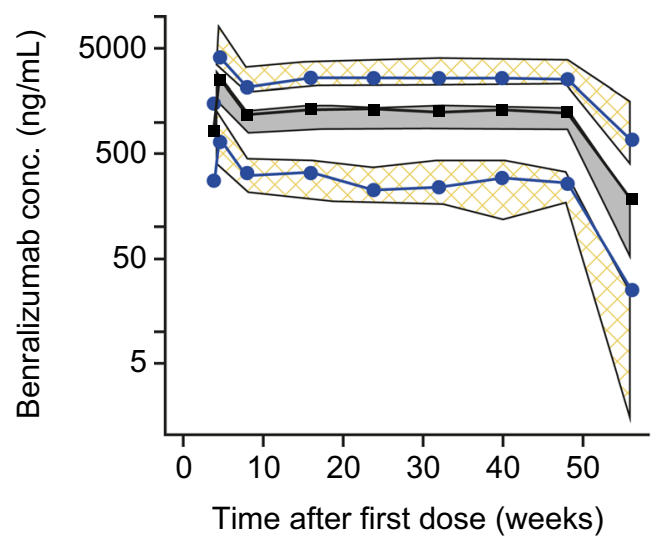

Study 18 Q4W

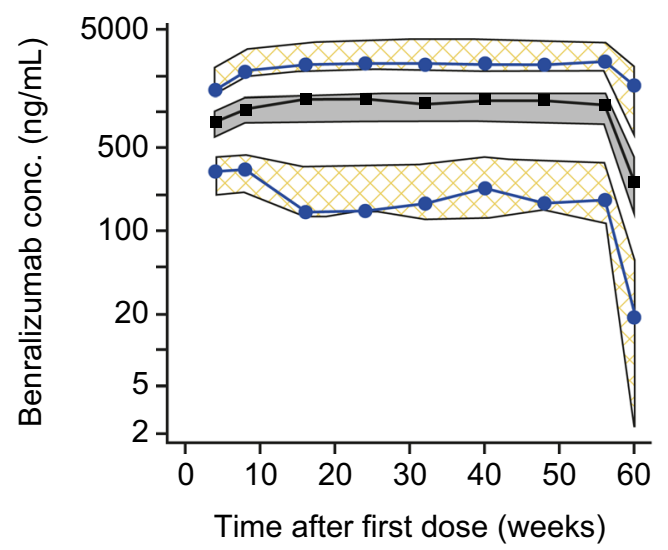

* Observed median

- Observed $5^{\text {th }} / 95^{\text {th }}$ percentile

- $90 \% \mathrm{PI}$ of median

¿ $90 \% \mathrm{PI}$ of $5^{\text {th }} / 95^{\text {th }}$ percentile
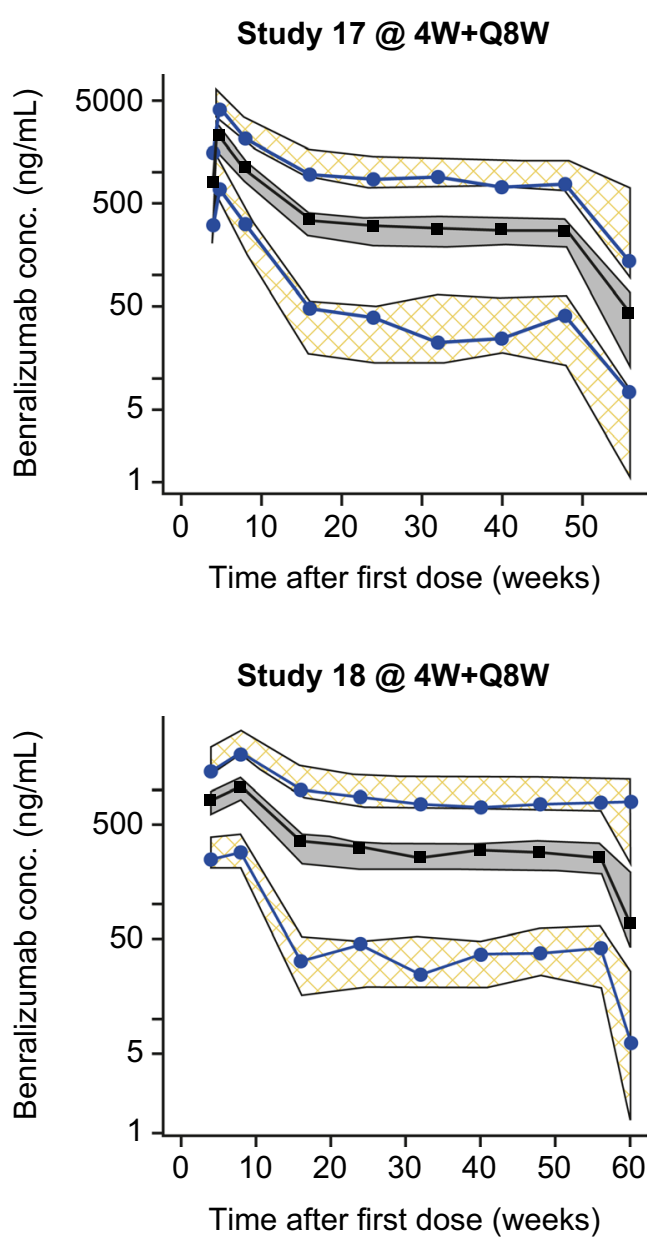

Fig. 3 Visual predictive check of the final updated pharmacokinetic model. Study $17=$ SIROCCO; Study $18=$ CALIMA. @ $4 W+Q 8 W$ every 4 weeks for the first three doses, followed by every 8 weeks, Conc. concentration, $I V$ intravenous, $P I$ prediction interval, $Q 4 W$ every 4 weeks

was administered in the upper arm of each patient; however, for each patient enrolled in the phase III program, subcutaneous benralizumab or placebo was administered in different anatomical sites (upper arm, abdomen, and thigh) following a prespecified rotation sequence $[11,12]$. The estimated subcutaneous bioavailability of benralizumab administered to the stomach or thigh was approximately $9 \%$ greater than the bioavailability after 


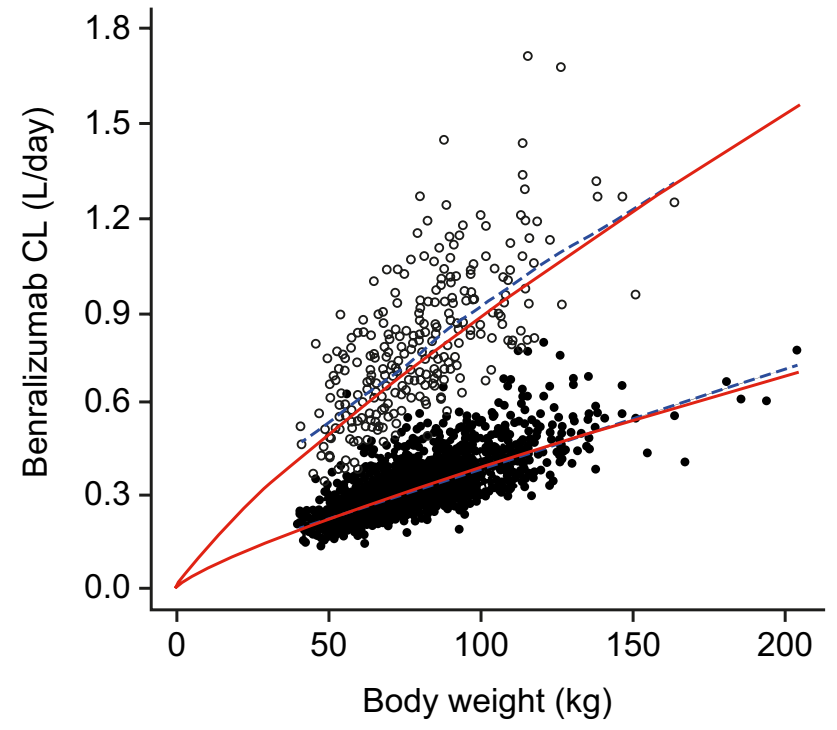

Fig. 4 Effects of body weight and ADA on the PK of benralizumab for patients with asthma. Closed circles represent CL in patients when ADA results were negative; open circles represent $\mathrm{CL}$ in patients when ADA results were positive. Red lines represent prediction curves [CL·(body weight/70) $\left.)^{0.807}\right]$, and blue lines represent locally weighted scatterplot smoothing (LOWESS). ADA antidrug antibodies, $C L$ clearance, $P K$ pharmacokinetics

administration to the upper arm; however, the magnitude of the effect was not considered clinically relevant. This result could support flexibility in the choice of an injection site for subcutaneous administration of benralizumab. Definitive assessment of relative bioavailability of benralizumab administered to different anatomic sites requires a single-dose PK study in healthy volunteers, with a more intensive sampling schedule (AMES study; NCT02968914).

As with other therapeutic IgGs, benralizumab is primarily eliminated through the reticuloendothelial system by the widely expressed proteolytic enzyme. From population modeling, the estimated typical CL for a $70-\mathrm{kg}$ patient was $0.291 \mathrm{~L} /$ day. Distribution of $\mathrm{IgG}$ and other recombinant proteins is usually restricted to extracellular fluid. The estimated $V_{\mathrm{c}}$ and $V_{\mathrm{p}}$ for benralizumab were $3.13 \mathrm{~L}$ and $2.52 \mathrm{~L}$, respectively, which is typical for IgG. The PK elimination half-life of benralizumab is approximately 15.5 days for patients with asthma.

Body weight was identified as a relevant covariate for CL, $V_{\mathrm{c}}$, and $V_{\mathrm{p}}$. As for other therapeutic mAbs, benralizumab CL increased with body weight. The effect of body weight was nearly allometric for benralizumab CL (power parameter estimate of 0.807). The allometric exponent for the effect of body weight was estimated as 0.803 for $V_{\mathrm{c}}$ and 0.528 for $V_{\mathrm{p}}$; however, body weight had no impact on efficacy or eosinophil depletion [15].
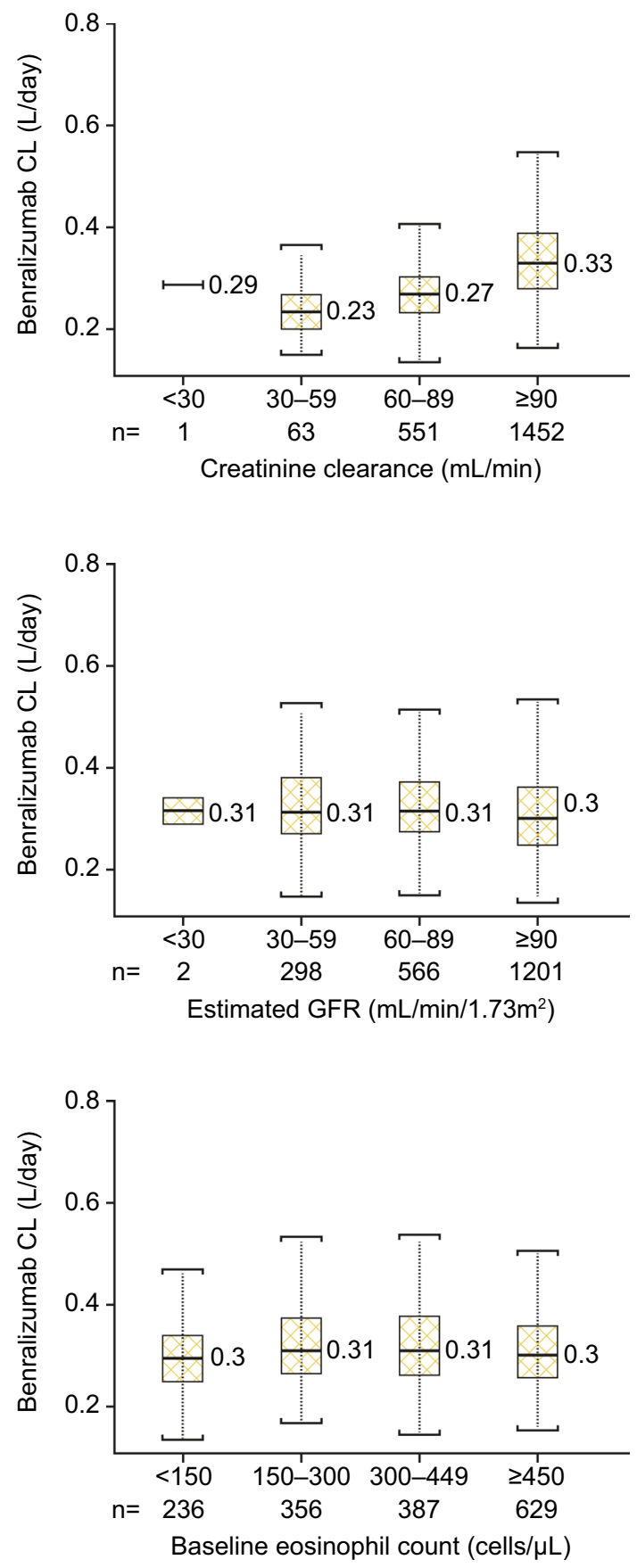

Fig. 5 No clinically meaningful effect of renal function or baseline eosinophil count on benralizumab CL. CLCR and eGFR grouped by values associated with levels of renal functions. $C L$ clearance, $C R C L$ creatinine clearance, $e G F R$ estimated glomerular filtration rate

Benralizumab was immunogenic in a small subset of patients. The development of ADAs was associated with a reduction in PK exposure. From the demographic covariate analysis, ADA status was the most influential covariate effecting benralizumab CL, resulting in a $>4000$-unit reduction in NONMEM OBJ value. Although the presence 
of ADAs was related to a marked increase (124\%) of benralizumab CL, it had no impact on the primary and key secondary efficacy endpoints in benralizumab phase III trials [15, 27]. The selection of $30 \mathrm{mg}$ every 8 weeks as the therapeutic dosage greatly reduced the impact of PK variability on efficacy outcome [11, 12].

Benralizumab treatment results in the rapid, near-complete depletion of blood eosinophil counts [5]. The lack of any trend in CL across groups suggests that eosinophil count does not have a meaningful impact on benralizumab CL, as evidenced by the absence of a nonlinear IL-5R-mediated elimination pathway of benralizumab in humans.

There was a general trend of increasing benralizumab CL with greater CRCL; however, calculated CRCL was proportional to body weight, whereas body weight allometrically affected benralizumab CL. A post hoc analysis using eGFR as a marker demonstrated that renal function had no effect on the PK of benralizumab.

IgG mAbs are not primarily cleared via the hepatic pathway; therefore, change in hepatic function is not expected to influence benralizumab CL. In this population analysis, no liver function markers (ALT, AST, and TBL) were identified as relevant PK covariates.

The effects of sex and race on benralizumab were considered insignificant. The statistical detection of such insignificant effects may stem from the large sample size of the dataset. Benralizumab mean exposure decreased slightly from adolescents (12-17 years of age) to older adults (65-75 years of age). The terminal half-life of benralizumab increased slightly with age, with median estimates of approximately 14 days in adolescents, 15 days in adults (18-64 years of age), and 17 days in older adults.

Benralizumab selectively targets and binds IL-5R $\alpha$, which is selectively expressed on eosinophils and basophils. IL-5R $\alpha$ is not expressed on hepatocytes, and treatment with benralizumab has no identified effect on other circulating cytokines, except for IL-5 and the eosinophil chemokines eotaxin-1 and eotaxin-2. From population analysis, commonly used small-molecule drugs (montelukast, paracetamol, proton pump inhibitors, macrolides, and theophylline/ aminophylline) had no effect on benralizumab CL. Together, these data indicate that the potential risk of interactions between benralizumab and other drugs is low.

\section{Conclusions}

Benralizumab PK data for adult and adolescent patients with asthma were pooled from nine phase I-III clinical trials and simultaneously modeled using a population approach. The PK of benralizumab are dose-proportional across a wide dosage range. The estimated disposition parameter values of benralizumab are typical for a human IgG. Body weight and
ADA status were identified as relevant PK covariates; however, further exposure-response analysis has demonstrated that neither impacts benralizumab efficacy at the $30-\mathrm{mg}$ every 8 weeks dosage. Baseline eosinophil count, hepatic and renal functions, anatomical subcutaneous injection site, and commonly used small-molecule drugs had no impact on the PK of benralizumab.

Acknowledgements The authors would like to respectfully acknowledge Matthew Hutmacher of A2PG (Ann Arbor, MI, USA) for his considerable contributions to the methodology, data analysis, and interpretation of this study. Sadly, he passed away before the development of this manuscript. Editing support, under the direction and guidance of the authors, and manuscript submission were provided by Debra Scates, PhD, of JK Associates, Inc. (Conshohocken, PA, USA) and Michael A. Nissen, ELS, of AstraZeneca (Gaithersburg, MD, USA). This support was funded by AstraZeneca.

\section{Compliance with Ethical Standards}

Funding This analysis was funded by AstraZeneca.

Conflict of interest Yen Lin Chia, Lorin Roskos, and Li Yan are employees of MedImmune LLC. Bing Wang was an employee of MedImmune LLC at the time of this analysis.

Ethics approval All procedures performed in studies involving human participants were in accordance with the ethical standards of the institutional and/or national research committee and with the 1964 Helsinki declaration and its later amendments or comparable ethical standards.

Informed consent Informed consent was obtained from all individual participants included in this study.

OpenAccess This article is distributed under the terms of the Creative Commons Attribution-NonCommercial 4.0 International License (http://creativecommons.org/licenses/by-nc/4.0/), which permits any noncommercial use, distribution, and reproduction in any medium, provided you give appropriate credit to the original author(s) and the source, provide a link to the Creative Commons license, and indicate if changes were made.

\section{References}

1. Garcia G, Taille C, Laveneziana P, Bourdin A, Chanez P, Humbert M. Anti-interleukin-5 therapy in severe asthma. Eur Respir Rev. 2013;22(129):251-7.

2. Hospers JJ, Schouten JP, Weiss ST, Postma DS, Rijcken B. Eosinophilia is associated with increased all-cause mortality after a follow-up of 30 years in a general population sample. Epidemiology. 2000;11(3):261-8

3. Price D, Wilson AM, Chisholm A, Rigazio A, Burden A, Thomas M, et al. Predicting frequent asthma exacerbations using blood eosinophil count and other patient data routinely available in clinical practice. J Asthma Allergy. 2016;9:1-12.

4. Talini D, Novelli F, Bacci E, Bartoli M, Cianchetti S, Costa F, et al. Sputum eosinophilia is a determinant of FEV1 decline in occupational asthma: results of an observational study. BMJ Open. 2015;5(1):e005748. 
5. Kolbeck R, Kozhich A, Koike M, Peng L, Andersson CK, Damschroder MM, et al. MEDI-563, a humanized anti-IL-5 receptor alpha $\mathrm{mAb}$ with enhanced antibody-dependent cell-mediated cytotoxicity function. J Allergy Clin Immunol. 2010;125(6):1344-53.

6. FASENRA ${ }^{\mathrm{TM}}$ (benralizumab) injection, for subcutaneous use (prescribing information). AstraZeneca Pharmaceuticals LP; 2017. https://www.accessdata.fda.gov/drugsatfda_docs/label /2017/761070s000lbl.pdf.

7. AstraZeneca. Fasenra receives approval in Japan (AstraZeneca press release). 19 January 2018. https://www.astrazeneca.com/media-centre/ press-releases/2018/fasenra-recieves-approval-in-japan-19012018.html.

8. FASENRA ${ }^{\mathrm{TM}}$ (benralizumab) injection, for subcutaneous use (summary of product characteristics). AstraZeneca Pharmaceuticals LP; 2018. http://ec.europa.eu/health/documents/commu nity-register/2018/20180108139598/anx_139598_en.pdf.2018.

9. Castro M, Wenzel SE, Bleecker ER, Pizzichini E, Kuna P, Busse WW, et al. Benralizumab, an anti-interleukin 5 receptor alpha monoclonal antibody, versus placebo for uncontrolled eosinophilic asthma: a phase $2 \mathrm{~b}$ randomised dose-ranging study. Lancet Respir Med. 2014;2(11):879-90.

10. Wang B, Yan L, Yao Z, Roskos LK. Population pharmacokinetics and pharmacodynamics of benralizumab in healthy volunteers and patients with asthma. CPT Pharmacomet Syst Pharmacol. 2017;6(4):249-57.

11. Bleecker ER, FitzGerald JM, Chanez P, Papi A, Weinstein SF, Barker $P$, et al. Efficacy and safety of benralizumab for patients with severe asthma uncontrolled with high-dosage inhaled corticosteroids and long-acting beta2-agonists (SIROCCO): a randomised, multicentre, placebo-controlled phase 3 trial. Lancet. 2016;388(10056):2115-27.

12. FitzGerald JM, Bleecker ER, Nair P, Korn S, Ohta K, Lommatzsch $\mathrm{M}$, et al. Benralizumab, an anti-interleukin-5 receptor alpha monoclonal antibody, as add-on treatment for patients with severe, uncontrolled, eosinophilic asthma (CALIMA): a randomised, double-blind, placebo-controlled phase 3 trial. Lancet. 2016;388(10056):2128-41.

13. Nair P, Wenzel S, Rabe KF, Bourdin A, Lugogo NL, Kuna P, et al. Oral glucocorticoid-sparing effect of benralizumab in severe asthma. N Engl J Med. 2017;376(25):2448-58.

14. Ferguson GT, FitzGerald JM, Bleecker ER, Laviolette M, Bernstein $\mathrm{D}$, LaForce $\mathrm{C}$, et al. Benralizumab for patients with mild to moderate, persistent asthma (BISE): a randomised, doubleblind, placebo-controlled, phase 3 trial. Lancet Respir Med. 2017;5(7):568-76.

15. Chia YL, Yan L, Yu B, Wang B, Barker P, Goldman M, et al. Relationship between benralizumab exposure and efficacy for patients with severe eosinophilic asthma. Clin Pharmacol Ther. https://doi. org/10.1002/cpt.1371 (epub 19 Jan 2019).

16. Busse WW, Katial R, Gossage D, Sari S, Wang B, Kolbeck R, et al. Safety profile, pharmacokinetics, and biologic activity of MEDI-563, an anti-IL-5 receptor alpha antibody, in a phase I study of subjects with mild asthma. J Allergy Clin Immunol. 2010;125(6):1237-44.

17. Laviolette M, Gossage DL, Gauvreau G, Leigh R, Olivenstein $\mathrm{R}$, Katial R, et al. Effects of benralizumab on airway eosinophils in asthmatic patients with sputum eosinophilia. J Allergy Clin Immunol. 2013;132(5):1086-96.

18. Nowak RM, Parker JM, Silverman RA, Rowe BH, Smithline H, Khan F, et al. A randomized trial of benralizumab, an antiinterleukin 5 receptor alpha monoclonal antibody, after acute asthma. Am J Emerg Med. 2015;33(1):14-20.

19. Gossage D, Geba G, Gillen A. A multiple ascending subcutaneous dose study of MEDI-563. A humanized anti-IL-5RA monoclonal antibody, in adult asthmatics. Annual congress of the European Respiratory Society (ERS); 2010: A1177.

20. Beal S, Sheiner LB, Boeckmann A, Bauer RJ. NONMEM user's guides (1989-2009). Ellicott City: Icon Development Solutions; 2009.

21. Kowalski KG, Hutmacher MM. Efficient screening of covariates in population models using Wald's approximation to the likelihood ratio test. J Pharmacokinet Pharmacodyn. 2001;28(3):253-75.

22. US FDA. Guidance for industry: pharmacokinetics in patients with impaired renal function-study design, data analysis, and impact on dosing and labeling. US FDA; 2010.

23. Byon W, Fletcher CV, Brundage RC. Impact of censoring data below an arbitrary quantification limit on structural model misspecification. J Pharmacokinet Pharmacodyn. 2008;35(1):101-16.

24. US FDA. Guidance for industry: population pharmacokinetics. US FDA; 1999.

25. Roskos LK, Davis CG, Schwab GM. The clinical pharmacology of therapeutic monoclonal antibodies. Drug Dev Res. 2004;61(3):108-20.

26. Richter WF, Bhansali SG, Morris ME. Mechanistic determinants of biotherapeutics absorption following SC administration. AAPS J. 2012;14(3):559-70.

27. Wang B, Yan L, Yao Z, Roskos LK. Population pharmacokinetics and pharmacodynamics of benralizumab in healthy volunteers and patients with asthma. CPT Pharmacometrics Syst Pharmacol. 2017;6(4):249-57. 